\title{
Disturbance in glucose metabolism in patients of lichen planus
}

\author{
A. S. M. Zakaria, Md. Kamal Hossain, Mohammed Saiful Islam Bhuiyan, Abida Sultana, \\ Mahmudur Rahman and Ommey Kulsom
}

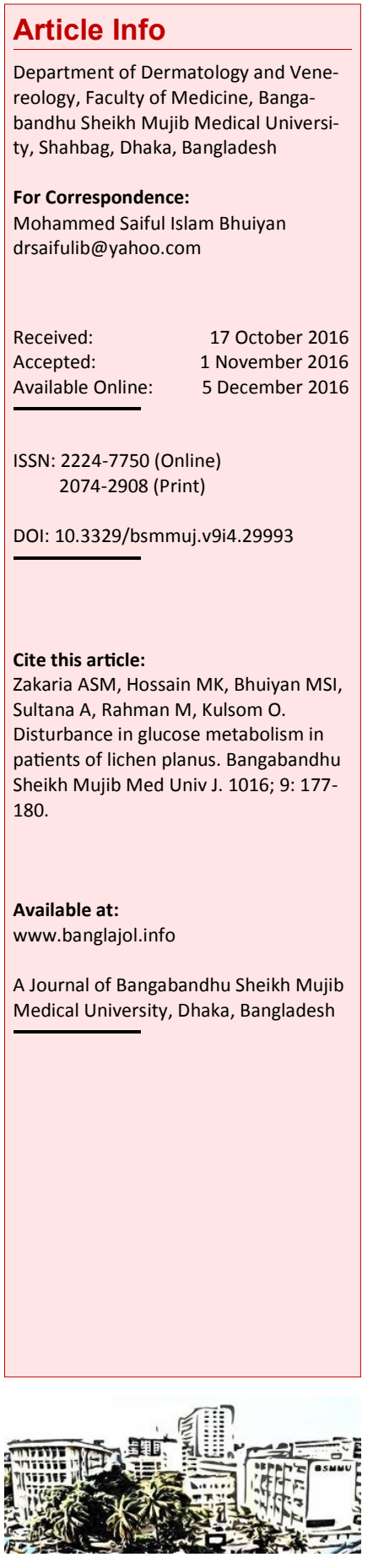

\section{Abstract}

The aim of this study was to see the association of lichen planus $(n=80)$ with glucose metabolism disturbance. Classic variety of lichen planus was the most common (76.3\%), followed by ashy dermatosis, hypertrophic, oral, actinic and nail lichen planus. The blood glucose level 2 hours after glucose drink was abnormal in 20 cases. $\mathrm{HbA}_{1} \mathrm{c}$ was abnormal in 7 cases. The mean homeostasis model of assessment formulation- insulin resistance index (HOMA-IR) was $2.1 \pm 1.6$ and it was higher $(>4.8)$ in $12.5 \%$ patients. Diabetes mellitus was found in 30 patients. Impaired glucose tolerance was found in 15 cases and high HOMA-IR was found in 10 cases. Total number of cases of abnormal glucose metabolism was found in 55 (68.8\%) cases of lichen planus. In conclusion, patients with lichen planus have higher risk of abnormal glucose metabolism specially diabetes mellitus.

\section{Introduction}

Lichen planus is an inflammatory keratotic dermatosis of unknown etiology, occurs in 0.5 $1.9 \%$ of the population. $\underline{1-2}$ Its classical clinical presentation is characterized by flat-topped, polygonal, papules or plaques of violet color. It affects primarily the flexure surface of the wrists, thighs, distal third of lower extremities, abdomen, genitals, nails and oral mucosa. Lichen planus is a pruritic, inflammatory disease of the skin, mucous membrane and hair follicles. It occurs throughout the world in all races. It is a common skin disease, comprising more than $0.5 \%$ of all dermatological visits. It may be familial in $1-2 \%$ of cases. 3

Glucose metabolism disturbance includes diabetes mellitus, impaired glucose tolerance and insulin resistance. Diabetes mellitus is a clinical syndrome characterized by hyperglycemia due to defects in insulin production, insulin action or both. Dysregulation of glucose, insulin and lipids directly related to physical signs in skin of patients with Diabetes mellitus. 4 The prevalence of diabetes (20-79 years) in South-East Asia was $7.6 \%$ and predicted to be 9.1\% in 2030 and in Bangladesh $6.1 \%$ in 2010 and predicted to be $7.4 \%$ in 2030.5 Impaired glucose tolerance has been referred to as prediabetes, indicating the relatively high-risk for the further development diabetes. The prevalence of impaired glucose tolerance is $4.0 \%$ in Bangladeshi population.6 Diabetes and impaired glucose tolerance can be diagnosed by using American Diabetes Association (ADA) criteria. Insulin resistance also indicates relatively high-risk for future development of diabetes. Insulin resistance can be measured by HOMA-IR (homeostasis model of assessment of insulin resistance index). 7

The etiopathogenesis of lichen planus remains unknown. The current trend is to consider lichen planus as an autoimmune process, mediated by T-cells and is triggered by antigen alterations on the cell surface of the basal layer of the epithelium.2 In addition, epidermal cells have shown abnormalities in the enzymatic activity, as well as defective carbohydrate expression, which might have a connection with hormones essential for the metabolic process. Recently, diabetes mellitus is considered to be associated with immunological changes, thus making a possible relationship between diabetes mellitus and lichen planus. .8

Some authors have demonstrated an incidence of diabetes mellitus between 14 and $85 \%$ in patients with lichen planus and reported abnormal glucose tolerance test results.9-11 However, some disagreed with this statement.12,13 Grinspan et al. (1966) reported a 40\% prevalence of diabetes mellitus in patients with oral lichen planus. $\underline{14}$ The variation in reported incidence of diabetes mellitus in patients with lichen planus may chiefly be explained by different methods and criteria used. In addition there is a wide variation in the frequency of glucose intolerance in these patients ranging 


\section{from 37 to $85 \% .9$}

These wide variations in previous results motivate further investigations concerning the incidence of diabetes mellitus in people with lichen planus. The study was conducted to see the prevalence of diabetes mellitus, impaired glucose tolerance and insulin resistance in patients with lichen planus.

\section{Materials and Methods}

This cross-sectional study was conducted on 80 patients of lichen planus from November 2013 to June 2015. Patient who had more than one dermatologic disease, pregnancy, subject with a history of neoplasia or malignancy, patient undergoing radiotherapy or chemotherapy, patient with autoimmune diseases such as lupus erythematosus, rheumatoid arthritis, Sjögren's syndrome or metabolic diseases such as diabetes, patient taking any systemic medication (including benzodiazepine, antidepressant, anabolic steroid, oral

\section{Table I}

\section{Distribution of lichen planus}

\begin{tabular}{|lc|}
\hline Variants & No. of patients \\
\hline Classic & 61 \\
Ashy dermatosis & 7 \\
Hypertrophic & 4 \\
Oral lichen planus & 4 \\
Nail & 3 \\
Actinic & 1 \\
\hline
\end{tabular}

Table II

Biochemical parameters of lichen planus

No. of patients $(n=80)$

\begin{tabular}{|c|c|}
\hline \multicolumn{2}{|l|}{ Fasting blood glucose } \\
\hline$<7 \mathrm{mmol} / \mathrm{L}$ & 62 \\
\hline$\geq 7 \mathrm{mmol} / \mathrm{L}$ & 18 \\
\hline \multicolumn{2}{|l|}{$\begin{array}{l}\text { Blood glucose } 2 \text { hours } \\
\text { after glucose drink }\end{array}$} \\
\hline$<7.8 \mathrm{mmol} / \mathrm{L}$ & 60 \\
\hline $7.8-11.0 \mathrm{mmol} / \mathrm{L}$ & 15 \\
\hline$\geq 11.1 \mathrm{mmol} / \mathrm{L}$ & 5 \\
\hline \multicolumn{2}{|l|}{$H b A_{1} c$} \\
\hline$<6.5 \%$ & 73 \\
\hline$\geq 6.5 \%$ & 7 \\
\hline \multicolumn{2}{|l|}{$H O M A-I R$} \\
\hline$\leq 4.8$ (Normal) & 70 \\
\hline$>4.9$ (High) & 10 \\
\hline
\end{tabular}
contraceptive pill, corticosteroid suppressing the immune system) within the last 30 days and smoker were excluded from the study.

Clinically selected cases of lichen planus were enrolled in the study with their consent and confirmed by histopathological examination of biopsy material from skin. Lesional skin biopsy specimen was taken in $10 \%$ formalin solution in a test tube. Then the test tube was sent in the Department of Pathology, Bangabandhu Sheikh Mujib Medical University for histopathological study for the diagnosis of lichen planus. Then $5 \mathrm{~mL}$ of blood sample was collected from the patients for determining fasting blood glucose level, oral glucose tolerance test, $\mathrm{HbA}_{1 \mathrm{c}}$ and HOMA-IR according to the protocol of the Department of Biochemistry, BSMMU.

Diagnosis of diabetes was based on plasma glucose criteria, either the fasting plasma glucose or the 2 hours value in the $75 \mathrm{~g}$ oral glucose tolerance test. $\underline{13} \quad \mathrm{HbA}_{1} \mathrm{C} \geq 6.5 \%$ or fasting plasma glucose $\geq 126 \mathrm{mg} / \mathrm{dL}$ (7.0 $\mathrm{mmol} / \mathrm{L})$ or 2 hours plasma glucose $\geq 200 \mathrm{mg} / \mathrm{dL}(11.1 \mathrm{mmol} / \mathrm{L}$ during an oral glucose tolerance test) or in a patients with classic symptoms of hyperglycemia or hyperglycemic crisis a random plasma glucose $\geq 200 \mathrm{mg} / \mathrm{dL}(11.1$ $\mathrm{mmol} / \mathrm{L})$.
Impaired glucose tolerance should be considered when fasting blood glucose $<7 \mathrm{mmol} / \mathrm{L}$ but blood glucose 2 hours after glucose drink is $7.8-11.1 \mathrm{~mol} /$ L. In states of insulin resistance, we should measure insulin resistance by HOMA-IR as follows:

HOMA-IR $=$ Fasting plasma insulin $\mathrm{mU} / \mathrm{mL} \mathrm{x}$ fasting plasma glucose $\mathrm{mmol} / \mathrm{L} / 22.5)$ [0.5 -4.8].7

\section{Results}

Among the total 80 patients, 31 belonged to age group of 31-40 years (mean age: $33.7 \pm 11.2$ years). Males were 58 in number whereas 22 were females. Regarding types of lichen planus, 61 were classic type, 7 were ashy dermatosis, 4 were hypertrophic, 4 were oral lichen planus (Table I).

The mean fasting blood glucose was found $5.6 \pm 1.0$ mmol/L. Abnormal fasting blood glucose $(\geq 7$ $\mathrm{mmol} / \mathrm{L}$ ) was found in 18 patients (Table II). The blood glucose level 2 hours after glucose drink was abnormal level in 20 cases. High $\mathrm{HbA}_{1} \mathrm{C} \quad(<6.5$ percent) was detected in 7 cases.

\section{Discussion}

Although lichen planus was described more than a century ago, its etiology remains little known. Many factors have been suggested for the pathogenesis, such as immunological mechanisms, genetic characteristics, drug use and infections, particularly viral infections. Recently four mechanisms are suggested as antigen-specific cell-mediated immune response (heat shock proteins, CD4+ T helper cells, $\mathrm{CD}+$ cytotoxic T-cells), nonspecific mechanism (epithelial basement membrane, mast cells, chemokines, matrix metaloproteinases), autoimmune response, humoral immunity (circulating auto antibodies to desmoglin 1 and 3). $\underline{15}$ The autoimmune background of lichen planus could support its association with different autoimmune diseases like diabetes mellitus. But different previous studies carried out to see the association lichen planus with diabetes mellitus or glucose intolerance gave confusing results. $.3,8,9,11,16,17$

This disease involves $2-5 \%$ of the general population with predominance in women. Its onset is in the $4^{\text {th }}$ and $5^{\text {th }}$ decades of life. This cross-sectional study was carried out with an aim to explore the association of diabetes mellitus, impaired glucose tolerance and insulin resistance in patients with lichen planus. Here, $38.8 \%$ of patients with lichen planus were in $4^{\text {th }}$ decade and the mean age was found $33.7 \pm 11.2$ years. Similarly, Manzoor et al. (2013) observed that the age of the patients varied from 15 to 54 years with $80 \%$ of the patients belonging to the 20 to 40 years age group. 18 The mean age $( \pm S D)$ was $30.2 \pm 7.9$ years, which is 
closely resembled with the present study. On the other hand, Panchal et al. (2015) 19 and Nosratzehi et al. (2015) 17 showed the mean age was $41.2 \pm 3.3$ years and $44.5 \pm 13.2$ years respectively for lichen planus patients, which are higher than the present study. In another study Denli et al. (2004)11 found the incidence occur in early age, where they found ages ranged between 5 and 78 years mean age and SD was $42.2 \pm 23.6$ years. Seyhan et al. (2007) 3 observed that the mean age was $42.9 \pm 14.1$ years with range from 14 to 72 years. In persons of European countries, it appears largely after the age of 20 and peaks between the age of 40 and 70 years. 3 Very few cases appear after age 80 years. 3 Similarly, the mean age was higher. $\underline{4,20}$

In the current study, lichen planus was predominant in male subject. Manzoor et al. (2013) observed 50 consecutive patients of lichen planus comprising of $54.0 \%$ male and $46.0 \%$ female, 18 which is similar with the current study. Similarly, Naheed et al. (2002) showed male to female ratio was 3:2, which is closely resembled with the present study. .4 On the other hand, Panchal et al. (2015), 19 Nosratzehi et al. (2015), $\underline{17}$ Atefi et al. (2012)므 and Brown et al. (1993) 1 found lichen planus predominant in females.

In the current study, classic variety is the most common $(76.3 \%)$, followed by ashy dermatosis, hypertrophic, oral, actinic and nail lichen planus. Panchal et al. (2015) observed that all the patients had cutaneous involvement; $40.5 \%$ presented with classic lichen planus, 13.5 oral lichen planus, $13.5 \%$ hypertrophic type, $10.8 \%$ pigmentosus type, $9.5 \%$ planopilaris type, $6.8 \%$ eruptive type, $2.7 \%$ had both oral and classic lichen planus, nail involvement and genital lichen planus type was observed in one of the patients (1.35\%). 19 In another study, Manzoor et al. (2013) observed $22.0 \%$ patients had nails affection. $\underline{18}$ Atefi et al. (2012) found $40.0 \%$ were presented only with skin lesions, $7.5 \%$ had only oral lesions and $52.4 \%$ had both skin and oral cavity lesions..20 Seyhan et al. (2007) observed patients with lichen planus, $20.0 \%$ had only skin lesions, $6.7 \%$ had only mucosal lesions, and $73.4 \%$ had both skin and oral lesions. $-\underline{3}$ The most frequently observed clinical form of skin involvement was classical distribution: Localized in $63.3 \%$ patients, generalized in $30.0 \%$ patients. Primary lesion sites were wrists in skin and buccal mucosa in mouth. Six $(20 \%)$ patients had no oral mucosal involvement and $80.1 \%$ showed mucosal lesions. Reticular lesions were seen most frequently $(66.7 \%)$, followed by ulcerative/erosive lesions $6.7 \%$.

This cross-sectional study was carried out with an aim to explore the association of diabetes mellitus, impaired glucose tolerance and insulin resistance in patients with lichen planus. Here, $77.5 \%$ patients had normal fasting blood glucose $(<7 \mathrm{mmol} / \mathrm{L})$ and $22.5 \%$ patients were diabetic $(\geq 7 \mathrm{mmol} / \mathrm{L}$ fasting blood glucose). The mean fasting blood glucose was found $5.6 \pm 1.0 \mathrm{mmol} / \mathrm{L}$, which is similar with Seyhan et al.. In another study, Nosratzehi et al. (2015) showed the mean fasting blood glucose in patient with oral lichen planus was $95.1 \pm 8.1 \mathrm{mg} /$ dL. 17 Atefi et al. (2012);므 Chalkoo (2010);프 and Ara et al. (2011)22 revealed that the prevalence of diabetes mellitus among patients with oral lichen planus is more than normal population. However, similar to the studies of Ansar et al. (2011) $\underline{23}$ and Borhan et al. (2009). $.4 \underline{4}$ Nosratzehi et al. (2015) $\underline{17}$ study illustrated no significant differences in fasting blood glucose test results between the two groups. Nosratzehi et al. (2015) 17 study indicated that there was no positive dependency between diabetes mellitus and oral lichen planus as $100 \%$ of oral lichen planus patients had normal fasting blood glucose values and no fasting blood glucose disorder was observed in the control group. Atefi et al.으 in 2012 found 14 patients (17.5\%) were classified as non-diabetic patients (fasting plasma glucose $<126 \mathrm{mg} / \mathrm{dL}$ ) but with impaired fasting glucose. Altogether, of 80 patients with lichen planus, $30(37.5 \%)$ had an impaired glucose metabolism. Also Nosratzehi et al.17 (2015) observed the prevalence of $17.5 \%$ for impaired fasting glucose in comparison with the prevalence of $12.8 \%$ in 1993 by Bussell et al..25 It seems that the relationship between diabetes and lichen planus is remarkable in Iran. Additionally, Nosratzehi et al. (2015) $\underline{17}$ investigated the relationship between impaired glucose tolerance or diabetes and the pattern of distribution of lichenoid lesions. This prevalence was found $14.6 \%$ by Christensen et al.,26 $30.3 \%$ by Nigan et al., 2 and $45.6 \%$ by Halevy and Feuerman...16

In this present study, $75 \%$ patients were found normal blood glucose level 2 hours after glucose drink. Unless there are concerns regarding possible hypoglycemia (blood glucose $<3.9 \mathrm{mmol} / \mathrm{L}$ [70 mg/ dL]), significant hyperglycemia (fasting blood glucose of $7.0 \mathrm{mmol} / \mathrm{L}$ [126 mg/dL] or higher; 2 hour postprandial blood glucose of $11.1 \mathrm{mmol} / \mathrm{L}$ [200 mg/dL] or higher), ketoacidosis, oral infection, or infection elsewhere in the body. In another study, Bhowmik et al.6 found the prevalence of diabetes mellitus $7.9 \%$ and impaired glucose tolerance $4.0 \%$ in Bangladesh community. Current study showed high prevalence of diabetes mellitus and impaired glucose tolerance 37.5 and $18 \%$ respectively in patients with lichen planus.

In the current study it was observed that 73 (91.2\%) patients were found $<6.5$ percent (normal) $\mathrm{HbA}_{1} \mathrm{C}$ and $7(8.8 \%)$ was diabetic $\left(\geq 6.5 \% \mathrm{HbA}_{1} \mathrm{c}\right)$. The mean $\mathrm{HbA}_{1} \mathrm{C}$ was found $5.6 \pm 0.7$ percent. Nosratzehi et al. 17 and Seyhan et al. 3 showed the mean $\mathrm{HbA}_{1} \mathrm{C}$ levels in patient with oral lichen planus was $5.1 \pm$ 1.3 and $5.9 \pm 0.6 \%$ respectively, which is comparable with the present study. Here, it was observed $12.5 \%$ patient had higher HOMA-IR. Seyhan et al. 3 found 
the mean HOMA score of $2.3 \pm 1.9$, which is comparable with the present study.

\section{Conclusion}

A strong association of glucose metabolism disturbance specially diabetes mellitus with lichen planus was found. Classic variants of lichen planus are more prone to abnormal glucose metabolism.

\section{References}

1. Brown RS, Bottomley WK, Puente E, Lavigne GL. A retrospective evaluation of 19.3 patients with oral lichen planus. J Oral Pathol Med. 1993; 22: 6972 .

2. Jacques CMC, Pereira ALC, Cabral MG, Cardoso AS, Ramos-e-Silva M. Oral lichen planus. Part I: Epidemiology, clinics, etiology, immunopathogeny and diagnosis. Skinmed 2003; 2: 342-49.

3. Seyhan M, Ozcan $H$, Sahin I, Bayram $N$, Karincaoglu Y. High prevalence of glucose metabolism disturbance in patients with lichen planus. Diabetes Res Clin Pract. 2007; 77: 198-202.

4. Naheed T, Akbar N, Akbar N, Shehzad M, Jamil $\mathrm{S}$, Ali T. Skin manifestations amongst diabetic patients admitted in a general medical ward for various other medical problems. Pakistan J Med Sci. 2002; 18: 291-96.

5. Shaw JE, Sicree RA, Zimmet PZ. Diabetes atlas: Global estimates of the prevalence of diabetes for 2010 and 2030. Diabetes Res Clin Pract, 2010; 87: 414.

6. Bhowmik B, Munir SB, Hossain IA, Siddiquee T, Diep LM, Mahmood S. et al. Prevalence of type 2 diabetes and impaired glucose regulation with associated cardiometabolic risk factors and depression in an urbanizing rural community in Bangladesh: A population-based cross-sectional study. Epidemiology 2012; 36: 422-32.

7. Matthews DR, Hosker JP, Rudenski AS, Naylor BA, Treacher DF, Turner RC. Homeostasis model assessment: Insulin resistance and $\beta$-cell function from fasting plasma glucose and insulin concentrations in man. Diabetologia 1985; 28: 412-19.

8. Lundstrom IM. Incidence of diabetes mellitus in patients with oral lichen planus. Int J Oral Surg. 1983; 12: 147-52.

9. Nigam PK, Sharma L, Agrawal JK, Singh G, Khurana SK. Glucose tolerance studies in lichen planus. Dermatologica 1987; 175: 284-89.

10. Gibson J, Lamey PJ, Lewis M, Frier B. Oral manifestations of previously undiagnosed noninsulin dependent diabetes mellitus. J Oral Pathol Med. 1990; 19: 284-87.

11. Denli YG, Durdu M, Karakas M. Diabetes and hepatitis frequency in 140 lichen planus cases in cukurova region. J Dermatol. 2004; 31: 293-98.

12. Ponte E, Tabaj D, Maglione M, Melato M. Diabetes mellitus and oral disease. Acta Diabetol. 2001; 38: 57-62.

13. Silverman S, Gorsky M, Lozada-Nur F, Giannotti $\mathrm{K}$. A prospective study of findings and management in 214 patients with oral lichen planus. Oral Surg Oral Med Oral Pathol. 1991; 72: 665-70.

14. Grinspan D, Diaz J, Villapol LO, Schneiderman J, Berdichesky R, Palese D et al. Lichen rubber planus of buccal mucosa. Its association with diabetes. Bull Soc Fr Dermatol Syphiligr. 1996; 3: 898-99.

15. Roopashree MR, Gondhalekar RV, Shashikanth MC, George J, Thippeswamy SH, Shukla A. Pathogenesis of oral lichen planus: A review. J Oral Pathol Med. 2010; 39: 729-34

16. Halvey S, Feuerman EJ. Abnormal glucose tolerance associated with lichen planus. Acta Derm Venereol. 1979; 59: 167-70.

17. Nosratzehi T, Arbabi-Kalati F, Arefpoor Z. Lack of association between diabetes mellitus and oral lichen plan. Brit J Dermatol. 2015; 91: 73-75.

18. Manzoor S, Qayoom S, Sultan J, Bhat YJ. Thyroid profile in lichen planus patients from Kashmir valley. Egyptian Dermatol Online J. 2013; 9: 1-5.

19. Panchal FH, Ray S, Munshi RP, Bhalerao SS, Nayak CS. Alterations in lipid metabolism and anti-oxidant status in lichen planus. IJD Focus: Lichen planus, 2015; 60: 439-55.

20. Atefi N, Majedi M, Peyghambari S, Ghourchian S. Prevalence of diabetes mellitus and impaired fasting blood glucose in patients with lichen planus. Med J Islam Rep Iran. 2012; 26: 22-26.

21. Chalkoo AH. Oral lichen planus with transaminase levels and diabetes. J Indian Acad Oral Med Radiol. 2010; 22: 1-3.

22. Ara SA, Mamatha GP, Rao BB. Incidence of diabetes mellitus in patients with lichenplanus. Int J Dent Clin. 2011; 3: 29-33.

23. Ansar A, Farshchian M, Ghasemzadeh SM. Comparison of the frequency of diabetes mellitus in the patients with lichen planus and normal controls: A case-control study. Dermatol Cosmet. 2011; 2: 78-84.

24. Borhan MK, Esfahani M, Bokharaei MM. Evaluation of median rhomboid glossitis and lichen planus in patients with diabetes mellitus. J Qazvin Univ Med Sci. 2009; 13: 56-60.

25. Bussell SN, Smales FC, Sutton RBO, Duckworth R. Glucose tolerance in patients with lesions of oral mucosa. Br J Dent J. 1979; 146: 186-88.

26. Christensen E, Holmstrup P, Wiberg-Jothrndrn F, Neumann-Jensen B, Pindborg JJ. Glucose tolerance in patients with oral lichen planus. J Oral Pathol. 1977; 6: 143-51. 